\title{
Sample Optimization for Rapid Identification of Nucleosides and Bases from Ascidian Extracts using ESI-MS/MS
}

\author{
Renata Takeara, ${ }^{a}$ Paula C. Jimenez, ${ }^{b}$ Letícia V. Costa-Lotufo, ${ }^{b}$ João L. C. Lopes ${ }^{a}$ and \\ Norberto P. Lopes ${ }^{*, a}$ \\ ${ }^{a}$ Departamento de Física e Química, Faculdade de Ciências Farmacêuticas de Ribeirão Preto, \\ Universidade de São Paulo, Av. do Café, s/n, 14040-903 Ribeirão Preto-SP, Brazil \\ ${ }^{b}$ Departamento de Fisiologia e Farmacologia, Faculdade de Medicina, Universidade Federal do Ceará, \\ CP 3157, 60430-270 Fortaleza-CE, Brazil
}

\begin{abstract}
Um método de espectrometria de massas sequencial com ionização por electrospray (IESEM/EM) foi desenvolvido para identificação dos nucleosídeos e bases em extratos de ascídias. Para este fim realizamos um estudo sistemático de preparo de amostra associado à análise de fragmentação de uma série de nucleosídeos e bases em IES-EM/EM. Estas abordagens constituem ferramentas analíticas importantes para screening rápido e determinação estrutural de nucleosídeos e bases em extratos de ascídias, os quais podem auxiliar nos estudos ecológicos do gênero.
\end{abstract}

Electrospray ionization tandem mass spectrometry (ESI-MS/MS) method was developed for identification of nucleosides and bases in extracts of ascidians. For this study a systematic sample preparation associated with the fragmentation pattern of a series of nucleosides and bases using ESI-MS/MS was done. These approaches constitute powerful analytical tools for rapid screening and structural assignment of nucleosides and bases in ascidian extracts.

Keywords: natural products, ESI-MS/MS, ascidian, nucleosides, glycosylamines

\section{Introduction}

Nucleosides are part of the nucleic acid compound family. They are glycosylamines made by attaching a nucleobase to a ribose or deoxyribose ring. Examples of these include cytidine, uridine, adenosine, guanosine, thymidine and inosine. Nucleosides are involved in the regulation and modulation of various physiological processes in the central nervous system (CNS). Adenosine can depress the excitability of CNS neurons and inhibit the release of various neurotransmitters presynaptically. ${ }^{1,2}$ There is growing pharmacological evidence based on studies with several animal models of seizure disorder that adenosine possesses anticonvulsivant activity. ${ }^{3}$ Inosine, the major biochemical metabolite of adenosine derived from oxidative deamination, stimulates axon growth in vitro and on the adult central nervous system. ${ }^{4}$ In addition, nucleosides also play an important role in growth and differentiation of the gastrointestinal tract, as

*e-mail: npelopes@fcfrp.usp.br well as in the maintenance of the immune response. ${ }^{5,6}$ Other closely related compounds are adenine arabinoside (Ara-A), an antiviral compound synthesized and commercialized by Burroughs Wellcome (now Glaxo Smith-Kline) and later found in the Mediterranean gorgonian Eunicella cavolini, and cytosine arabinoside (ARA-C), a potent antileukemic agent commercialized by Upjohn (now Pharmacia). These compounds are derived from spongothymidine and spongouridine isolated in the early 1950s from the Caribbean sponge Criptotethya crypta. ${ }^{7}$

Nucleosides are present in several species of ascidians. Thymidine was isolated from Trididemnum cereum, ${ }^{8}$ Aplidium pantherinum, ${ }^{9}$ Didemnum voeltzkowi,${ }^{10}$ Eudistoma sp., ${ }^{11}$ and Atriolum robustum. ${ }^{12}$ Uridine was reported in Aplidium pantherinum, ${ }^{9}$ Botryllus schlosseri, ${ }^{13}$ and Atriolum robustum. ${ }^{12} 2$ '-deoxyuridine and 2'-deoxyinosine were identified in the ascidians Trididemnum cereum ${ }^{8}$ and Aplidium pantherinum. ${ }^{9}$ Hypoxanthine was isolated from Trididemnum cereum $^{8}$ and adenosine was present in Eudistoma sp. ${ }^{11}$ Based on these comments we can accept that ascidians are potential 
sources for nucleosides, which can also serve as a chemical taxonomic marker.

In recent years, it has been shown that liquid chromatography (LC) coupled to electrospray ionization mass spectrometry (ESI-MS) is a powerful tool to separate and identify natural products. ${ }^{14-16}$ Structure elucidation of natural compounds in complex mixtures has also been possible by use of direct injections of crude extracts into the electrospray ionization tandem mass spectrometry (ESI-MS/MS) followed by isolation into the analyzer, even using small quantities of plant material or other biological samples. ${ }^{17,18}$ More recently, systematic investigation on ionization processes and gas phase chemistry involved in natural products fragmentation for fingerprint analysis has been useful from plants, ${ }^{19,20}$ algae,${ }^{21}$ and microorganisms. ${ }^{22}$ The literature reports several examples of this approach for alkaloids, ${ }^{19}$ sesquiterpene lactones, ${ }^{20}$ carotenoids, ${ }^{21}$ polyketides,${ }^{22-23}$ quinones,${ }^{24}$ retinoids ${ }^{25}$ and $\beta$-carbolines. ${ }^{26}$

The present paper proposes a sample optimization for rapid identification of nucleosides and bases using electrospray ionization tandem mass spectrometric (ESIMS/MS) screening method in ascidian extracts. In this study, we report several fast techniques of sample preparation followed by a direct ESI-MS/MS spectrometric method for characterization of the nucleosides.

\section{Experimental}

\section{Materials, standards and sample preparation}

Colonies of the ascidian E. vannamei (1460 g, wet weight) were collected on the intertidal zone of the beach rocks at Taiba Beach (São Gonçalo do Amarante, Ceará State, Brazil) and frozen. The material was extracted with $\mathrm{MeOH}(1 / 5, \mathrm{~m} / \mathrm{v})$ at room temperature and the solvent was evaporated in vacuum to afford $46.10 \mathrm{~g}$ of the crude extract. The nucleosides adenosine and guanosine were isolated from the methanolic extract of the ascidian $E$. vannamei and were used as standards.

2'-deoxyguanosine, 2'-deoxyinosine, 2'-deoxyuridine, uridine, thymidine, and hypoxanthine isolated from the methanolic extract of the ascidian Didemnum psammatodes were also used as standards.

Standards of uracil, thymine, guanine, and adenine were purchased from Sigma. A solution of each nucleoside and base $\left(0.1 \mathrm{mg} \mathrm{mL}^{-1}\right)$ was prepared in $\mathrm{MeOH} / \mathrm{H}_{2} \mathrm{O} 1: 1$ and stored in refrigerator.

The studied compounds are listed in Table 1 and their respective structures are shown in Figure 1.
Table 1. Substituents of pyrimidine and purine derivatives

\begin{tabular}{lccc}
\hline Pyrimidines (Figure 1, structure A) & $\mathrm{R}^{1}$ & $\mathrm{R}^{2}$ & $\mathrm{R}^{3}$ \\
\hline (1) Uracil & $\mathrm{H}$ & $\mathrm{H}$ & $\mathrm{H}$ \\
(2) Thymine & $\mathrm{CH}_{3}$ & $\mathrm{H}$ & $\mathrm{H}$ \\
(3) Uridine & $\mathrm{H}$ & $\mathrm{H}$ & Ribosyl \\
(4) 2'-Deoxyuridine & $\mathrm{H}$ & $\mathrm{H}$ & 2'-Deoxyribosyl \\
(5) Thymidine & $\mathrm{CH}_{3}$ & $\mathrm{H}$ & 2'-Deoxyribosyl \\
\hline
\end{tabular}

Purines (Figure 1, structure B)

\begin{tabular}{lccc}
\hline (6) Adenine & $\mathrm{NH}_{2}$ & $\mathrm{H}$ & $\mathrm{H}$ \\
(7) Hypoxanthine & $\mathrm{OH}$ & $\mathrm{H}$ & $\mathrm{H}$ \\
(8) Guanine & $\mathrm{OH}$ & $\mathrm{NH}_{2}$ & $\mathrm{H}$ \\
(9) Adenosine & $\mathrm{NH}_{2}$ & $\mathrm{H}$ & Ribosyl \\
(10) 2'-Deoxyadenosine & $\mathrm{NH}_{2}$ & $\mathrm{H}$ & 2'-Deoxyribosyl \\
(11) 2'-Deoxyinosine & $\mathrm{OH}$ & $\mathrm{H}$ & 2'-Deoxyribosyl \\
(12) Guanosine & $\mathrm{OH}$ & $\mathrm{NH}_{2}$ & Ribosyl \\
(13) 2'-Deoxyguanosine & $\mathrm{OH}$ & $\mathrm{NH}_{2}$ & 2'-Deoxyribosyl \\
\hline
\end{tabular}

(A)<smiles>[R]c1c([R])n([R3])c(=O)[nH]c1=O</smiles><smiles>[R]c1nc([R])c2ncn([R])c2n1</smiles>

Figure 1. Structures of pyrimidine (A) and purine (B) derivatives (for substituents, see Table 1).

Several samples from the extracts were prepared to analyze the presence of nucleosides and bases. The methods of preparation for each sample are listed in Table 2.

\section{Mass spectrometry}

Methanol (HPLC grade) and de-ionized water (MilliQ) were used throughout the whole study. ESI mass spectra, precursor and product ions scans were acquired in positive ion mode and recorded on a quadrupole-time of flight instrument (UltrOTOF-Q, Bruker Daltonics, Billerica, MA). Conditions: capillary voltage $3400 \mathrm{~V}$; dry gas temperature, $180^{\circ} \mathrm{C}$; dry gas flow, $4 \mathrm{~L} \mathrm{~h}^{-1}$; nebulizer gas, nitrogen. NaTFA $10 \mathrm{mmol} \mathrm{L}^{-1}$ was used as standard for internal and external calibration. For tandem mass spectrometry analysis (ESIMS/MS) nitrogen was used as collision gas.

\section{Results and Discussion}

\section{Analysis of standards by ESI-MS}

The mass spectra of the guanine and adenine obtained from scan mode showed an intense protonated molecule signal $[\mathrm{M}+\mathrm{H}]^{+}$in addition to the cationized molecules. However, $[\mathrm{M}+\mathrm{Na}]^{+}$of hypoxanthine, thymine, 2'-deoxyuridine and thymidine and $[\mathrm{M}+\mathrm{K}]^{+}$ 
Table 2. Sample preparation for identification of nucleosides from ascidian Eudistoma vannamei

\begin{tabular}{ll}
\hline Sample & Method of preparation \\
\hline 1 & addition of $\mathrm{MeOH}$, centrifugation, clean up of supernatant in solid phase extraction using Sepack- $\mathrm{C}_{18}$ cartridge \\
2 & addition of $\mathrm{H}_{2} \mathrm{O}$, centrifugation to eliminate the insoluble residue \\
3 & addition of $\mathrm{MeOH} / \mathrm{H}_{2} \mathrm{O} 3: 7$, centrifugation to eliminate the insoluble residue \\
4 & addition of acetonitrile/ $\mathrm{H}_{2} \mathrm{O} 2: 8$, centrifugation to eliminate the insoluble residue \\
5 & addition of $\mathrm{MeOH}$, centrifugation, clean up of supernatant in solid phase extraction using Sepack-silica cartridge, elution with more 1.0 \\
& $\mathrm{~mL}$ of $\mathrm{MeOH}$ \\
6 & addition of EtOAc, centrifugation to eliminate the soluble fraction, solubilization of the residue in $\mathrm{MeOH} / \mathrm{H}_{2} \mathrm{O} 1: 1$, centrifugation to \\
& eliminate the insoluble fraction, clean up of supernatant in solid phase extraction using Sepack-silica cartridge, elution with more $1.0 \mathrm{~mL}$ \\
& of $\mathrm{MeOH} / \mathrm{H}_{2} \mathrm{O}$
\end{tabular}

of 2'-deoxyinosine, guanosine and adenosine proved to have a more intense peak than its $[\mathrm{M}+\mathrm{H}]^{+}$. The intensity of $[\mathrm{M}+\mathrm{Na}]^{+}$and $[\mathrm{M}+\mathrm{K}]^{+}$ions will depend on the quality of the water, solvent and other conditions, but the balance of $[\mathrm{M}+\mathrm{Na}]^{+}$and $[\mathrm{M}+\mathrm{K}]^{+}$ion may also be used to confirm the molecular mass.

ESI-MS/MS data of the protonated and cationized nucleosides and bases are shown in Table 3. Small neutral losses corresponding to the molecules $\mathrm{NH}_{3}(-17), \mathrm{HCN}$ $(-27), \mathrm{H}_{2} \mathrm{NCN}(-42)$ and $\mathrm{HNCO}(-43)$ are the major pathways. The elimination of masses 116 and 132 indicates the presence of deoxyribosyl and ribosyl, respectively, in the molecule. This cleavage, connected with hydrogen transfer, is depicted in Figure 2.

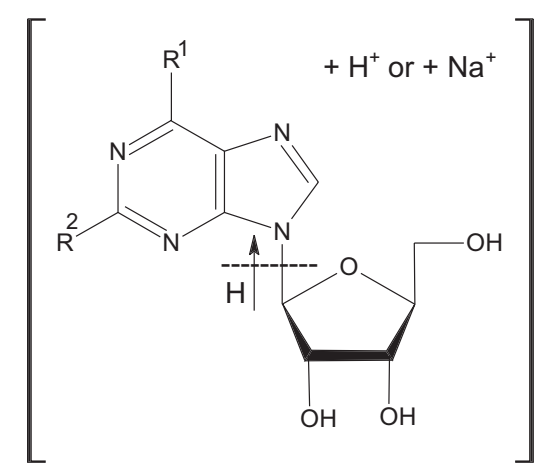

Figure 2. Cleavage of glycosidic C-N bond.

Analysis of the extracts obtained from the ascidians $E$. vannamei and D. psammatodes by ESI-MS

Figure 3A shows the ESI mass spectrum of the first sample obtained from the extract derived from the ascidian E. vannamei. This sample was prepared by solubilization of the extract in $\mathrm{MeOH}$ and cleans up using Sepack- $\mathrm{C}_{18}$. The presence of the nucleoside adenosine (9) was confirmed by the ion of $m / z 268$ from the $[\mathrm{M}+\mathrm{H}]^{+}$(see Table 4$)$. However, other ions were present in the mass spectra, and the accuracy mass indicate the absence of nitrogen on their molecular formula. The addition of $\mathrm{MeOH}$ in the extract may have solubilized other constituents less polar than the nucleosides.

In the second, third and fourth sample obtained by solubilization of the extract from E. vannamei in $\mathrm{H}_{2} \mathrm{O}$, $\mathrm{MeOH} / \mathrm{H}_{2} \mathrm{O}$ and acetonitrile $/ \mathrm{H}_{2} \mathrm{O}$, respectively, the nucleosides were not extracted in high amount compared with other compounds (see Figures 3B, 3C and 3D). It is possible that the clean up process of the extract using a Sepack- $\mathrm{C}_{18}$ cartridge is necessary to retain these compounds that are not nucleosides, and also confirm the less polar characteristic of those.

Figure $3 \mathrm{E}$ shows the ESI mass spectrum of the fifth sample obtained from the extract of E. vannamei. This sample was prepared by solubilization of the extract in $\mathrm{MeOH}$ and cleans up using Sepack - silica followed by elution with $\mathrm{MeOH}$. The nucleosides were not extracted by this method yet. Only the ion of $m / z, 136$ from the $[\mathrm{M}+$ $\mathrm{H}]^{+}$of the adenine base (6) was present in the mass spectra of this sample obtained from scan mode (see Figure 3E). Maybe the nucleosides, by their polarity (presence of sugar in the molecule), retained in the silica cartridge and the elution with $\mathrm{MeOH}$ was not enough to remove them.

The sixth sample was obtained by solubilization of the extract from E. vannamei in EtOAc, elimination of the soluble fraction, solubilization of the residue in $\mathrm{MeOH} /$ $\mathrm{H}_{2} \mathrm{O}$ 1:1 and clean up using Sepack - silica followed by elution with $\mathrm{MeOH} / \mathrm{H}_{2} \mathrm{O}$. The presence of the nucleoside adenosine (9), ions of $\mathrm{m} / \mathrm{z}, 268$ and $\mathrm{m} / \mathrm{z}, 290$ from the [M+ $\mathrm{H}]^{+}$and $[\mathrm{M}+\mathrm{Na}]^{+}$, respectively, was confirmed in the mass spectra (see Figure 3F). However, other ions were present. The process of extract solubilization in EtOAc was not enough for remove the low polarity impurities that were in the extract as those ions were observed in the mass spectra. In the following stage, the use of $\mathrm{MeOH} /$ $\mathrm{H}_{2} \mathrm{O} 1: 1$ to dissolve the sample was adequate to get the nucleoside adenosine and the elution with another $1.0 \mathrm{~mL}$ 

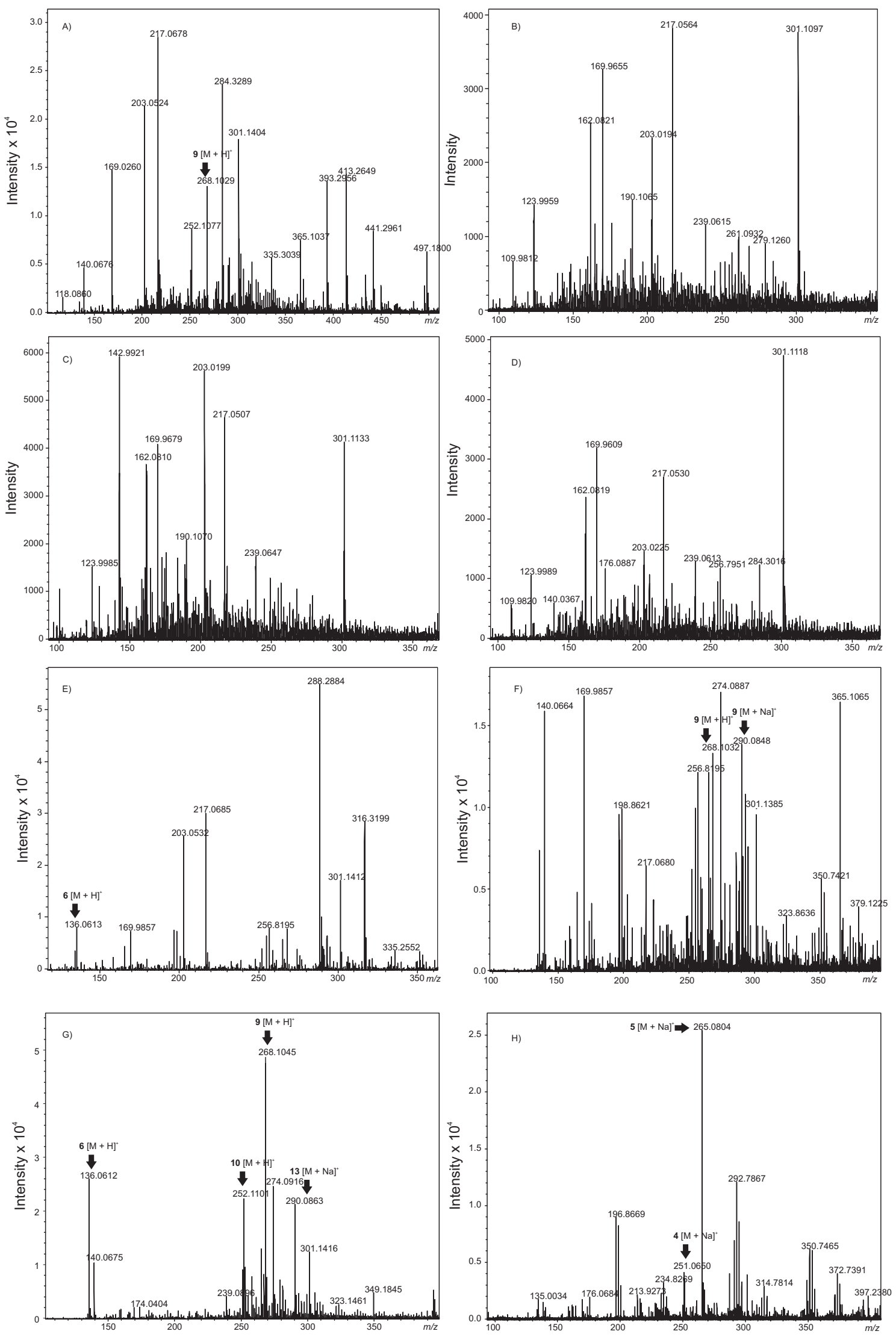

Figure 3. ESI mass spectra in the positive ion mode. (A) Sample 1 of extract from E. vannamei, (B) Sample 2 of extract from E. vannamei, (C) Sample 3 of extract from E. vannamei, (D) Sample 4 of extract from E. vannamei, (E) Sample 5 of extract from E. vannamei, (F) Sample 6 of extract from E. vannamei, (G) Sample 7 of extract from E. vannamei, (H) Sample 7 of extract from D. psammatodes. 

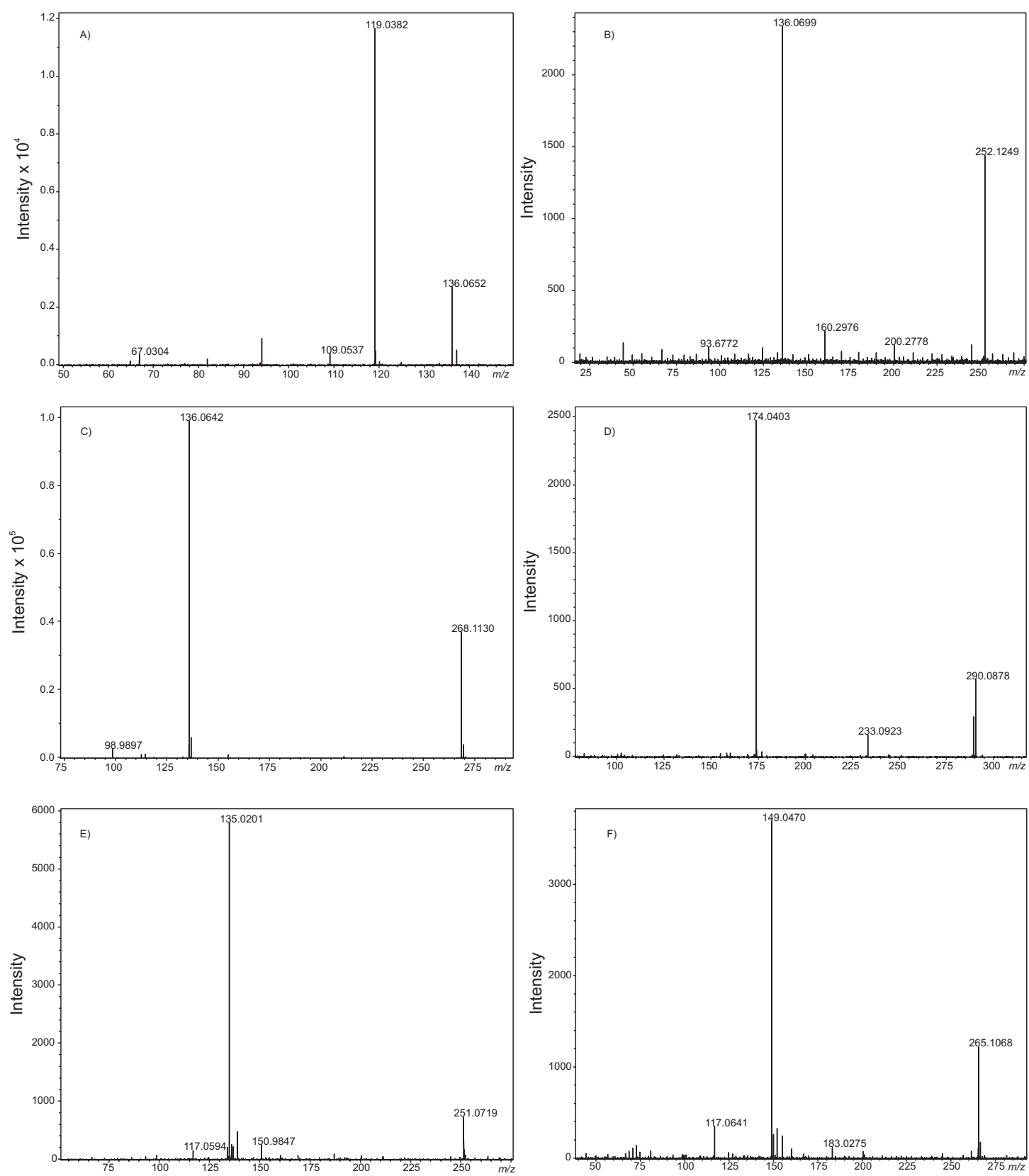

Figure 4. ESI-MS/MS. (A) ion of $m / z 136\left([\mathrm{M}+\mathrm{H}]^{+}\right)$of adenine from the sample 7 of extract of E. vannamei, (B) ion of $m / z 252\left([\mathrm{M}+\mathrm{H}]^{+}\right)$of 2 deoxyadenosine from the sample 7 of extract of E. vannamei, (C) ion of $\mathrm{m} / z 268\left([\mathrm{M}+\mathrm{H}]^{+}\right)$of adenosine from the sample 7 of extract of $E$. vannamei, (D) ion of $m / z, 290\left([\mathrm{M}+\mathrm{Na}]^{+}\right)$of 2'-deoxyguanosine from the sample 7 of extract of E. vannamei, (E) ion of $m / z 251\left([\mathrm{M}+\mathrm{Na}]^{+}\right)$of 2'-deoxyuridine from the obtained sample of extract of D. psammatodes, (F) ion of $\mathrm{m} / \mathrm{z} 265\left([\mathrm{M}+\mathrm{Na}]^{+}\right)$of thymidine from the obtained sample of extract of $D$. psammatodes.

of $\mathrm{MeOH} / \mathrm{H}_{2} \mathrm{O}$ was enough to remove that and other impurities of the silica, as other ions that were not nucleosides were present in the mass spectra.

Figure 3G shows the ESI mass spectrum of the seventh sample obtained by solubilization of the extract from $E$. vannamei in $\mathrm{H}_{2} \mathrm{O}$ at $60{ }^{\circ} \mathrm{C}$, clean up using Sepack- $\mathrm{C}_{18}$ followed by elution with $\mathrm{H}_{2} \mathrm{O}$ and $\mathrm{H}_{2} \mathrm{O} / \mathrm{MeOH}$. This method proved to be the best to get the nucleosides and eliminate the impurities. The use of $\mathrm{H}_{2} \mathrm{O}$ at $60{ }^{\circ} \mathrm{C}$ was adequate to solubilize only more polar compounds, like nucleosides. The elution of the sample with $\mathrm{H}_{2} \mathrm{O}$ removed impurities like salts, sugars and other compounds of high polarity. Then, the elution with $\mathrm{H}_{2} \mathrm{O} / \mathrm{MeOH}$ 8:2 removed the nucleosides of the $\mathrm{C}_{18}$ cartridge (see Figure $3 \mathrm{G}$ ). The presence of nucleoside 2'-deoxyadenosine (10) was confirmed by the ion of $\mathrm{m} / z 252$ from the $[\mathrm{M}+\mathrm{H}]^{+}$, adenosine (9) by the ion of $\mathrm{m} / z 268$ from the $[\mathrm{M}+\mathrm{H}]^{+}$and 2'-deoxyguanosine (13) by the ion of $\mathrm{m} / \mathrm{z}, 290$ from the $[\mathrm{M}+\mathrm{Na}]^{+}$(see Table 4 ), and the base adenine $(\mathbf{6})$ was confirmed by the ion of $m / z, 136$ from the $[\mathrm{M}+\mathrm{H}]^{+}$. The 
Table 3. Collision-induced dissociation of the molecules of the anaytes ${ }^{\mathrm{a}}$

\begin{tabular}{lcc}
\hline Analyte & {$[\mathrm{M}+\mathrm{H}]^{+}$or $[\mathrm{M}+\mathrm{Na}]^{+}$} & MS/MS \\
\hline (1) Uracil & 113 & $113(79 \%,-0), 96(72 \%,-7), 70(100 \%,-43)$ \\
(2) Thymine & 127 & $127(77 \%,-0), 110(100 \%,-17)$ \\
(6) Adenine & 136 & $136(23 \%,-0), 119(100 \%,-17), 109(3.5 \%,-27)$ \\
(8) Guanine & 152 & $152(49 \%,-0), 135(100 \%,-17), 110(36 \%,-42)$ \\
(3) Uridine & 267 & $267(70 \%,-0), 135(93 \%,-132)$ \\
(4) 2'-Deoxyuridine & 251 & $251(12 \%,-0), 135(100 \%,-116)$ \\
(5) Thymidine & 265 & $265(33 \%,-0), 149(100 \%,-116)$ \\
(9) Adenosine & 268 & $268(37 \%,-0), 136(100 \%,-132)$ \\
(10) 2'-Deoxyadenosine & 252 & $252(61 \%,-0), 136(100 \%,-116)$ \\
(11) 2'-Deoxyinosine & 275 & $275(40 \%,-0), 159(100 \%,-116)$ \\
(12) Guanosine & 284 & $284(55 \%,-0), 152(100 \%,-132)$ \\
(13) 2'-Deoxyguanosine & 290 & $290(23 \%,-0), 174(100 \%,-116)$ \\
\hline
\end{tabular}

${ }^{a}$ Neutral losses leading to the formation of the product ions from $[\mathrm{M}+\mathrm{H}]^{+}$or $[\mathrm{M}+\mathrm{Na}]^{+}$ions are given in parentheses

Table 4. Accurate mass measurements and formula assignments for 4, 6, 9, 10 and 13

\begin{tabular}{lcccc}
\hline Ion & Formula & Exact mass & Actual mass & Mass error/(ppm) \\
\hline$\left[\mathbf{4 + \mathrm { Na } ] ^ { + }}\right.$ & $\mathrm{C}_{9} \mathrm{H}_{12} \mathrm{~N}_{2} \mathrm{NaO}_{5}{ }^{+}$ & 251.0643 & 251.0650 & +2.7 \\
{$[\mathbf{5}+\mathrm{Na}]^{+}$} & $\mathrm{C}_{10} \mathrm{H}_{14} \mathrm{~N}_{2} \mathrm{NaO}_{5}^{+}$ & 265.0800 & 265.0804 & +1.5 \\
{$[\mathbf{6}+\mathrm{H}]^{+}$} & $\mathrm{C}_{5} \mathrm{H}_{6} \mathrm{~N}_{5}^{+}$ & 136.0617 & 136.0612 & -3.6 \\
{$[\mathbf{9}+\mathrm{H}]^{+}$} & $\mathrm{C}_{10} \mathrm{H}_{14} \mathrm{~N}_{5} \mathrm{O}_{4}^{+}$ & 268.1040 & 268.1045 & +1.8 \\
{$[\mathbf{1 0}+\mathrm{H}]^{+}$} & $\mathrm{C}_{10} \mathrm{H}_{14} \mathrm{~N}_{5} \mathrm{O}_{3}^{+}$ & 252.1091 & 252.1101 & +3.9 \\
{$[\mathbf{1 3}+\mathrm{Na}]^{+}$} & $\mathrm{C}_{10} \mathrm{H}_{13} \mathrm{~N}_{5} \mathrm{NaO}_{4}^{+}$ & 290.0865 & 290.0863 & -0.6 \\
\hline
\end{tabular}

ESI tandem mass spectrometric experiments of these compounds were also obtained (see Figures 4A, 4B, 4C and 4D) and the losses are showed in Table 3.

With the aim to confirm the efficiency of the method of sample preparation the extract of the ascidian Didemnum psammatodes was submitted to the same technique of the seventh sample. From the previous fractionation and purification of this extract were isolated the nucleosides 2'-deoxyguanosine (13), 2'-deoxyinosine (11), 2'-deoxyuridine (4) and thymidine (5) in small quantities. Figure $3 \mathrm{H}$ shows the ESI mass spectrum of the sample obtained from ascidian D. psammatodes. The presence of the nucleoside thymidine (5) was confirmed by the ion of $\mathrm{m} / z 265$ from the $[\mathrm{M}+\mathrm{Na}]^{+}$and 2'deoxyuridine (4) by the ion of $\mathrm{m} / \mathrm{z} 251$ from the $[\mathrm{M}+$ $\mathrm{Na}]^{+}$(see Table 4). The ESI tandem mass spectrometric experiments of these compounds were also obtained (see Figures $4 \mathrm{E}$ and $4 \mathrm{~F}$ ) and the losses are showed in Table 3.

\section{Conclusions}

In this paper, we report the development of a simple and rapid technique of sample preparation followed by a direct ESI-MS/MS spectrometric method for characterization of nucleosides and bases from ascidian extracts. Three nucleosides and one base in a methanolic extract from the ascidian $E$. vannamei and two nucleosides in the methanolic extract from the ascidian D. psammatodes were identified. The successful determination of the nucleosides in $E$. vannamei and D. psammatodes shows that ESI-MS and ESIMS/MS can serve as powerful analytical tools for rapid screening of nucleosides in ascidian extracts, avoiding time and material-consuming efforts in chemical characterization of marine organisms.

\section{Acknowledgments}

The authors acknowledge FAPESP, CAPES and CNPq (Instituto do Milênio) for financial support and fellowships.

\section{References}

1. Coradetti, R.; Lo Conte, G.; Moroni, F.; Passani, M.B.; Pepeu, G.; Eur. J. Pharmacol. 1984, 104, 19.

2. Schmidt, C.; Bellingham, M.C.; Richter, D.W.; J. Physiol. 1995, 483, 769.

3. Ballarin, M.; Herrera-Marschitz, M.; Cassa, M.; Ungerstedt, U.; Neurosci. Lett. 1987, 83, 338.

4. Benowitz, L.I.; Goldberg, D.E.; Irwin, N.; Prog. Brain Res. 2002, 137, 389.

5. Uady, R.; Stringel, G.; Thomas, R.; Quan, R.; J. Pediatr. Gastroenterol. Nutr. 1990, 10, 497.

6. Carver, J.D.; J. Nutr. 1994, 129, 144.

7. Bergmann, W.; Feeney, R.J.; J. Am. Chem. Soc. 1950, 72, 2809. 
8. Demattè, N.; Guerriero, A.; De Clauser, R.; De Stanchina, G.; Lafargue, F.; Cuomo, V.; Pietra, F.; Comp. Biochem. Physiol. 1985, $81 B, 479$.

9. Kim, J.; Pordesimo, E.O.; Toth, S.I.; Schmitz, F.J.; Altena, I.V.; J. Nat. Prod. 1993, 56, 1813.

10. Mitchell, S.S.; Pomerantz, S.C.; Concepción, G.P.; Ireland, C.M.; J. Nat. Prod. 1996, 59, 1000.

11. Schupp, P.; Pochner, T.; Edrada, R.; Ebel, R.; Berg, A.; Wray, V.; Proksch, P.; J. Nat. Prod. 2003, 66, 272.

12. Kehraus, S.; Gorzalka, S.; Hallmen, C.; Iqbal, J.; Müller, C.E.; Wright, A.D.; Wiese, M.; König, G.M.; J. Med. Chem. 2004, 47, 2243.

13. Usov, A.I.; Slanchev, K.I.; Smirnova, G.P.; Ivanova, A.P.; Stefanov, K.L.; Popov, S.S.; Andreev, S.N.; Russ. J. Bioorg. Chem. 2002, 28, 147.

14. Albert, K.; Krucker, M.; Glaser, T.; Schefer, A.; Lienau, A.; Zeeb, D.; Anal. Bioanal. Chem. 2002, 372, 25.

15. Pinto, A. C.; Silva, D. H. S.; Bolzani, V. S.; Lopes, N. P.; Epifanio, R. A.; Quim. Nova 2002, 25 suppl. 1, 45.

16. Crotti, A.E.M.; Vessecchi, R.L.; Lopes, J.L.C.; Lopes, N.P.; Quim. Nova 2006, 29, 287.

17. Fredenhagen, A.; Derrien, C.; Gassmann, E.; J. Nat. Prod. 2005, 68, 385 .

18. Maurin, A.J.M.; Iamamoto, Y.; Lopes, N.P.; Lindsay-Smith,
J.R.; Bonato, P.S.; J. Braz. Chem. Soc. 2003, 14, 322.

19. Pivatto, M.; Crotti, A.E.M.; Lopes, N.P.; Castro-Gamboa, I.; De Rezende, A.; Viegas Jr., C.; Young, M.C.M.; Furlan, M.; Bolzani, V.S.; J. Braz. Chem. Soc. 2005, 16, 1431.

20. Crotti, A.E.M.; Lopes, J.L.C.; Lopes, N.P.; J. Mass Spectrom. 2005, 40, 1030.

21. Guaratini, T.; Lopes, N.P.; Pinto, E.; Colepicolo, P.; Gates, P.J.; Chem. Commun. 2006, 39, 4110.

22. Fonseca, T.; Lopes, N.P.; Gates, P.J.; Staunton, J.; J. Am. Soc. Mass Spectrom. 2004, 15, 325.

23. Lopes, N.P.; Gates, P.J.; Wilkins, J.P.G.; Staunton, J.; Analyst 2002, 127, 1224.

24. Vessecchi, R.L.; Nascimento, P.G.B.D.; Lopes, J.N.C.; Lopes, N.P.; J. Mass Spectrom. 2006, 41, 1219.

25. Guaratini, T.; Gates, P.J.; Cardozo, K.H.M.; Campos, P.M.B.G.M.; Colepicolo, P.; Lopes, N.P.; Eur. J. Mass Spectrom. 2006, 12, 71 .

26. Lopes, N.P.; Fonseca, T.; Wilkins, J.P.G.; Staunton, J.; Gates, P.J.; Chem. Commun. 2003, 1, 72.

Received: December 7, 2006 Web Release Date: August 20, 2007

FAPESP helped in meeting the publication costs of this article. 